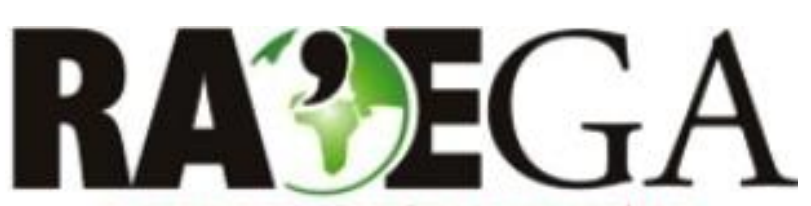

O ESPAÇO GEOGRÁFICO EM ANÁLISE

\title{
OS SENTIDOS DO DESLOCAMENTO EM CORPO DE BAILE, DE GUIMARÃES ROSA
}

\section{THE MEANINGS OF DISPLACEMENT IN GUIMARÃES ROSA'S CORPO DE BAILE}

\author{
Gabriel Túlio de Oliveira Barbosa \\ Programa de Pós Graduação em Geografia \\ Universidade Federal de Minas Gerais - UFMG \\ Belo Horizonte, MG, Brasil \\ e-mail:gabrielt.oliveirab@gmail.com \\ Julia Fonseca de Castro \\ Programa de Pós Graduação em Geografia \\ Universidade Federal de Minas Gerais - UFMG \\ Belo Horizonte, MG, Brasil \\ e-mail:juliafcastro2@gmail.com
}

Recebido em: 20/02/2015

Aceito em: 24/11/2015

\section{Resumo}

$O$ ato de mover-se pelo espaço é marcado por amplos significados que são produzidos por sujeitos para os quais a mobilidade quase sempre representa mais do que um deslocamento físico. Para refletir sobre a produção de sentidos para o deslocamento espacial, propõe-se uma leitura de Corpo de Baile, de Guimarães Rosa. A imagem central dos "corpos em baile" neste livro remete ao movimento como alternativa de vida, muitas vezes como única opção de sobrevivência, ou como solução que resulta da esperança de mudança de vida no contexto do sertão; é também construída por sujeitos em crise, em que a estrada representa seu próprio devir. Este artigo apresenta uma reflexão sobre os mais diversos sentidos produzidos pelos personagens rosianos no que tange à temática da viagem, articulando-os aos conceitos de errância, travessia e peregrinatio. Os personagens das novelas Dão-Lalalão (O Devente), Recado do Morro e Estória de Lélio e Lina estimulam uma reflexão sobre o deslocamento como experiência socioespacial e simbólica no contexto do 
sertão. A partir da análise interpretativa das narrativas, o resultado da discussão levantada sugere a viagem como um dos aspectos centrais das estórias e, sobretudo, como condição extremamente arraigada nas relações espaciais e nas noções de ciclos que se sucedem no movimento da vida e da experiência.

Palavras-chave: Deslocamento espacial; Guimarães Rosa; Errância; Travessia; Peregrinatio.

\section{Abstract}

The action of moving corresponds to a multitude of meanings that are created by subjects to whom moving often means more than the movement itself. In order to ponder about the meanings surrounding movements, we suggest reading Corpo de Baile, by Guimarães Rosa. The central image of moving in Corpo de Baile portrays mobility as a life-path, many times as the sole choice for survival, or as a solution, which stems from the longing for a change of life in the context of dry rural areas in the Sertão; this is created by subjects in crisis to whom the road represents their own becoming. We suggest pondering about the most diverse meanings created by fictional/real characters, and articulating them with the concepts of errancy, displacement and diaspora. The characters of the short stories Dão-Lalalão (O Devente), Recado do Morro and Estória de Lélio e Lina foster the discussion about moving as a symbolic experience in the uneven context of the dry rural areas in Sertão. According to the interpretative analysis of the narratives, the discussion proposed by this paper suggests the displacement as a central aspect of the stories and especially as an important issue for spatial relations and notions concerning the movement of life and experience.

Keywords: Mobility, Guimarães Rosa; Errancy; Displacement; Peregrinatio.

\section{INTRODUÇÃO}

\subsection{Contextualização}

O homem é um ser móvel. Refletir sobre a faceta móvel da humanidade é retomar longa trajetória desde seus primórdios, em movimentos em busca de sobrevivência, de abrigo e alimentação, passando por situações relacionadas às mais diversas civilizações: guerras, disputas e, também, conquistas territoriais. Atualmente, as sociedades contemporâneas seguem em intensa 
movimentação cuja complexidade resulta na (re) configuração de fluxos espaciais diversos. Envolto em tais fluxos ou deslocamentos coletivos está o homem: sujeito-móvel ou sujeito-movente que transforma os passos dados e as direções tomadas em construções de sentido articuladas aos significados de vida (sobrevivência e experiência) e de morte (fim do movimento, fim do caminho).

Seja integrando-se aos grandes fluxos espaciais, criando caminhos ao entrecortar o movimento das massas e/ou movendo-se à margem da dinâmica mobilidade global, o sujeito experimenta o deslocamento espacial de formas distintas. Pode experimentá-lo como ato de liberdade e autonomia - como nos deslocamentos com fins de lazer e viagem, por exemplo -, como também pode experimentar a mobilidade como atividade imposta cujo ritmo e direção não correspondem a seus desejos mas às convenções e regras sociais deslocamentos cotidianos entre lar e local de trabalho. É estimulante pensar a produção de sentidos para o ato de deslocar-se a partir do entendimento das relações entre mobilidade, espaço e subjetividade: mobilidade espacial como ato autônomo ou como ato de sujeição?

A relação entre mobilidade e lugar, mais do que as articulações conceituais entre mobilidade e espaço, pode ser explorada a partir das indagações anteriores. Sob o ponto de vista do sujeito que produz sentido para o deslocamento, o afastamento de seu lugar cotidiano representa mais do que um distanciamento físico, mas uma forma de libertação. Afinal, o lugar, dimensão da vida cotidiana em que se expressam as emoções, a afetividade e a intersubjetividade, expõe, também, o conjunto de normas, valores e papeis sociais que, não raramente, apresentam um aspecto opressor. É também no lugar que o tempo demonstra suas marcas, sendo o espaço da velhice, da doença e da morte; espaço em que os limites da vida são bem marcados e dos quais se pretende fugir, ainda que provisoriamente, por meio da mobilidade.

Autonomia, fuga do cotidiano, evasão, mas, também, exigência social, fluxos de trabalho, mobilidade forçada: os sentidos das mobilidades são múltiplos e em alguma medida contraditórios. Para explorar a complexidade envolta na produção de sentido para $\mathrm{o}$ ato de deslocar-se pelo espaço - e, 
decorrentemente, pelo tempo -, a projeção estética das obras literárias pode indicar um rico potencial para explorar o tema, a partir do foco em personagens cujas vozes, percepções, medos e desejos se articulam a situações e conjunturas específicas, favorecendo, assim, uma interpretação generosa sobre a questão.

As obras literárias em seus diversos gêneros - romances, poesias, novelas, contos, etc - podem representar importante produção de caráter reflexivo e/ou ficcional que possibilita o debate sobre aspectos da realidade socioespacial compreendidos em estudos geográficos e em outras áreas do conhecimento. A opção por tratar questões socioespaciais a partir do diálogo com obras e escritores da literatura é uma tendência que se faz presente no âmbito da geografia e em outros campos interdisciplinares. Um dos exemplos notórios da possibilidade da literatura constituir uma interpretação rica para compreender as dinâmicas de natureza espacial, trata-se, justamente, da consagrada obra de Guimarães Rosa. A obra rosiana apresenta aspectos discutidos tanto pela geografia e pela literatura, quanto pelas ciências sociais, psicologia, lingüística, ciências agrárias, demografia, dentre outras.

O presente artigo propõe a leitura de Corpo de Baile, de Guimarães Rosa, com o objetivo geral de discutir a produção de sentidos para o ato de deslocar-se e os diversos significados da viagem nas experiências itinerantes dos personagens desta obra. Nas novelas que constituem o livro em questão', o destino itinerante dos personagens manifesta-se por múltiplas instâncias causais, de modo que é possível reconhecer o tema da viagem ou do deslocamento como um dos eixos agregadores das histórias ${ }^{2}$.

\footnotetext{
${ }^{1}$ A primeira edição de Corpo de Baile de 1956 era composta por dois volumes, com a distribuição das sete estórias. Por motivos práticos e interesses editoriais, a versão mais difundida do livro remonta a composição da terceira edição de 1965, em que a disposição da obra é constituída por três volumes independentes: Manuelzão e Miguilim, No Urubuquaquá, no Pinhém e Noites do sertão. Optamos pela análise da edição comemorativa de 50 anos do lançamento do livro (1956-2006), que recupera a edição original e o caráter da totalidade da obra e das profundas conexões entre as estórias.
}

${ }^{2}$ Em "Campo Geral", o ciclo da viagem marca a passagem do mundo infantil de Miguilim para a vida adulta. "Uma estória de amor" revela as lembranças da vida itinerante de Manuelzão, antes de se fixar na Fazenda da Samarra. Nas demais estórias, os sujeitos viajantes adquirem distintas facetas: Lélio é o vaqueiro errante em busca do amor em "Estória de Lélio e Lina"; Soropita, o viajante atormentado de "Dão-Lalalão"; e Grivo é o narrador poético encomendado pelo patrão para o relato de uma viagem pelos gerais em "Cara de Bronze". Já em "Recado do Morro", que retrata uma espécie de expedição científica em que a viagem entrelaça um recado repassado e transmutado, tal como um fio narrativo, Pedro Orósio é o viajante local, da terra, analfabeto que, em contraparte ao viajante letrado, branco, representado pelo 


\subsection{Corpos em baile - a viagem em Guimarães Rosa}

O motivo da viagem, da travessia e das diversas modalidades de mobilidades perpassa praticamente todas as obras de Guimarães Rosa, desde Sagarana (1984) até Primeiras Estórias (2008)³. Ao analisar as diversas variações da palavra "viagem" no "Léxico de Guimarães Rosa", de Nilce Sant'Anna Martins (2008) é possível reiterar a grande relevância do tema do deslocamento e dos seres viajantes na literatura rosiana. Dispersas por praticamente todos os livros do autor, são recorrentes expressões como viabundo (de via+bundo, por analogia a vagabundo), viageiro, viajadamente (à maneira de quem viaja), viajadinho, viajor, viajorno (combinação de via[gem] e jorno [do italiano, giorno]), viajoso (de viajado). Todas essas variantes terminológicas remetem à característica errante dos sujeitos móveis do sertão mineiro, que carregam em sua ancestralidade a característica de nômades ou errantes desde o período das primeiras migrações humanas pelos chapadões do Brasil Central, quando saíram em busca das áreas de formação aberta do Cerrado, dos abrigos naturais e de seus recursos vegetais.

Historicamente, a convivência dessas comunidades com os ricos ecossistemas do Cerrado permitiu um modo de vida hábil para escrever no espaço suas grafias, suas geografias, a partir do conhecimento e da harmonia com a terra, com o mundo natural, onde natureza e "homem humano" (ROSA, 2001, p. 624) são um só. Tendo o Rio São Francisco como linha d'água condutora, essas populações se depararam com a dispersão e multiplicação de currais e fazendas por suas terras a partir do século XVIII, momento em que os povos do Cerrado passaram a combinar as heranças de seus antepassados com a cultura "móvel" do pastoreio, do trabalho essencialmente itinerante dos vaqueiros o que pode ser compreendido com a criação de uma nova relação de mobilidade pelo território-sertão.

Na obra de Guimarães Rosa, o vínculo da vida sertaneja com o universo da pecuária extensiva é tratado de forma intensa e rica, retratando o sertanejo

personagem Seo Olquiste, realiza uma viagem de retorno à região onde nasceu. "Buriti" encerra e renova o "ciclo de bailes" com a reaparição de Miguilim, já adulto, conduzindo um jipe à Fazenda do Buriti Bom.

\footnotetext{
${ }^{3}$ Sagarana e Primeiras Estórias foram publicadas originalmente nos anos de 1946 e 1962, respectivamente.
} 
vestido pelo couro, com chapéu, sujigola, algibeira e gibão, aprendendo a domar cavalos, mulas e bois, com laços e cabrestos, rompendo novas travessias sertão a fora, versando viagens a cavalo pelas estradas. O tema do deslocamento nas obras do autor é frequente e apresenta nuances diferenciadas, como, por exemplo, em Grande Sertão: veredas e em Corpo de Baile. Em ambas as obras, a transitoriedade dos personagens permeia 0 imenso "mar de territórios" do sertão: ora como consequência das andanças dos jagunços e de suas estratégias em um verdadeiro campo de guerra, no caso de Grande Sertão: veredas; ora pelas instabilidades vividas pelos protagonistas de Corpo de Baile, cujos deslocamentos se dão em momentos de crise e de tentativas individuais de superação de suas condições econômicas, afetivas e existenciais. Frente à transitoriedade dos personagens, a condição comum das travessias nas duas obras converge para um mesmo universo dominado pelo latifúndio, onde não há espaço para os pequenos e médios proprietários rurais.

O "homem muito provisório", citado por Riobaldo, personagem principal de Grande Sertão: veredas, não corresponde apenas ao jagunço, o guerreiro das grandes batalhas, mas também ao homem comum do campo, 0 trabalhador anônimo em sua luta diária. Estes homens são contrapostos aos "sujeitos de terra definitivos", que conseguem perpetuar o poder da propriedade ${ }^{4}$. Ambos os arquétipos correspondem à expressão da dinâmica de mobilidades nos territórios do sertão produzida pela concentração fundiária, na qual uma minoria detém as melhores condições de posse da terra e, portanto, de fixação, enquanto uma enorme massa se põe em movimento. No livro focalizado neste artigo, os "corpos em baile" desenhados por Guimarães Rosa são constituídos por homens e mulheres que integram uma massa de múltiplas identidades: catrumanos, matutos, sertanejos, ribeirinhos, cangaceiros, jagunços, geraizeiros, enxadeiros, lavradores e todos aqueles que, para sobreviver, necessitam conduzir-se por incertos destinos, lugares

\footnotetext{
${ }^{4}$ Exemplos dos "sujeitos de terra definitivos" são o ganancioso dono de terras Seu Habão de Grande Sertão: veredas, e os grandes fazendeiros de Corpo de Baile: lô Liodoro de "Buriti"; o "Cara-de-Bronze", da novela homônima; Seo Senclér da Fazenda do Pinhém, em "Estória de Lélio e Lina"; e o Frederico Freyre, dono da Samarra em "Uma Estória de Amor".
} 
desconhecidos. Fazem parte de uma população que, marginalizada, conduz-se à deriva.

A imagem central do deslocamento em Corpo de Baile ${ }^{5}$ remete à mobilidade como alternativa de vida, muitas vezes como única opção de sobrevivência, ou como solução que resulta da esperança de mudança de vida; é também construída por sujeitos em crise para os quais a estrada representa seu próprio devir. Os personagens de Corpo de Baile são, em sua grande maioria, empregados, que ocupam a posição de sujeitos serviçais e, em grande medida, vivem à mercê da flutuação das ofertas de trabalho temporário, das adversidades climáticas no campo ou de fenômenos mais amplos, como a modernização do Estado e urbanização que, ainda que de maneira rarefeita, atingem seu território.

Compreender esse fato, todavia, não é o mesmo que construir uma leitura sobre a mobilidade de tais personagens - que representam parcela importante da população do sertão e, também, do Brasil —, de modo a esvaziar a multiplicidade de concepções que sustentam a criação de sentidos para o deslocamento, taxando tais sujeitos como massa homogênea em trânsito constante. Para além da imagem que indica um movimento sincronizado no território do sertão, encontram-se sujeitos cujas escolhas, por mais que sejam condicionadas e cerceadas pelas relações de poder dominantes no sertão e perversidades do sistema econômico instaurado, são efetivas e determinam o curso da dança sugerida por Guimarães Rosa. O título da obra, Corpo de Baile - corpo que dança - sugere, a partir da dança, a referência do movimento coreografado em que o imprevisível surge a partir da liberdade criativa e do improviso.

O presente artigo justifica-se pela identificação da necessidade de reflexões sobre a questão da mobilidade espacial centradas na questão da subjetividade e nos aspectos histórico-culturais implicados. Questiona-se,

\footnotetext{
${ }^{5}$ As sete novelas, apesar de aparentemente serem independentes, são articuladas entre si, não só pelo aparecimento de alguns personagens em mais de uma das estórias, mas também pela coesão contextual do meio social dos gerais no livro. Além disso, Soares (2007) ainda esclarece que a unidade de conjunto do livro pode ser sustentada também por outros dois importantes fatores: o fato de serem sete estórias, que são também o número dos conjuntos perfeitos (os dias da criação, os planetas da cosmologia tradicional, os ramos da árvore cósmica...); e também pelo título que as articula: "trata-se de um corpo, um organismo resultante do inter-relacionamento de suas partes constitutivas." (SOARES, 2007, p. 40)
} 
portanto, sobre as identidades dos povos do sertão figurados no livro em questão: seriam viajantes, nômades, migrantes, refugiados, seres errantes, existenciais, ou assumiriam, de uma só vez, todas essas identidades? Qual a potência do deslocamento para a transformação da vida de tais personagens ficcionais/reais? Quais perspectivas podem se abrir a partir da reflexão sobre os personagens viajantes de Corpo de Baile em relação à própria discussão conceitual que envolve o tema da viagem e o fenômeno das mobilidades humanas sob o prisma socioespacial?

O objetivo do artigo é refletir sobre os sentidos de deslocamento ou mobilidade espacial produzidos em Corpo de Baile e na articulação de tais sentidos aos conceitos de errância, travessia e peregrinatio.

\section{MATERIAIS E MÉTODOS}

O presente artigo foi construído a partir de um conjunto de premissas metodológicas que orientaram a interpretação acerca do tema da viagem e do deslocamento no livro Corpo de Baile de acordo com os objetivos definidos. Em primeiro lugar, tais premissas dizem respeito à escolha por discutir a produção de sentidos para 0 ato de deslocar-se espacialmente através da análise de uma obra literária. De modo complementar, os pressupostos do presente trabalho compreendem as relações tanto entre arte e ciência, quanto entre discurso científico e discurso literário e, também, os desdobramentos dessas relações para as abordagens na área de estudos em que dialogam estudos geográficos e literários.

Nesse sentido, é importante refletir sobre a literatura como espaço em que a subjetividade se apresenta e que, por ser explicitada, traz possibilidades de interpretação que podem ser precisas e, também, aprofundadas no que diz respeito aos sentimentos, imaginação, utopias e outras percepções implicadas nos deslocamentos espaciais. Ainda que as noções de deslocamento espacial e dinâmica socioespacial façam parte das discussões conceituais que envolvem as categorias de análise geográfica e também de outros temas aos quais tem se dirigido a geografia (tal como migrações e desterritorialização), as obras literárias apresentam percepções e sentimentos que ultrapassam os limites rígidos das disciplinas científicas, como a obra de Guimarães Rosa. 
Nesse sentido, tanto a literatura e a geografia, como outras áreas do saber científico e das artes,podem se complementar para um melhor entendimento sobre a produção de sentido para o ato de deslocamento pelo espaço-tempo.

Sobre a relação entre conhecimento socioespacial e literatura, reflete Cássio Hissa:

\begin{abstract}
Por toda a obra da literatura circulam saberes que se interpenetram. Como negar a existência de um saber geográfico, de um saber sociológico, de um saber ecológico na literatura de Guimarães Rosa? Fragmentos de sua obra ilustram as enormes possibilidades que a literatura oferece: interpretações sobre o mundo, leitura do que se pode compreender como realidade. Lê-se o mundo sem a intenção de lhe atribuir a verdade única, que ele não possui. (HISSA, 2006, p. 290, grifos do autor).
\end{abstract}

As artes, em sentido amplo, representam excelente possibilidade para discutir os significados do deslocamento espacial. O discurso literário, ao contrário do discurso estritamente científico ${ }^{6}$, é propenso à multiplicidade de interpretações, pois, ao não bloquear nenhuma das possíveis leituras de mundo, ele se abre para a diversidade de experiências, de linguagens. As obras da literatura muitas vezes dizem o que parece ser indizível por meio da ciência. As palavras são escolhidas e combinadas com liberdade expressiva, a partir de arquiteturas exploratórias que buscam alcançar o leitor: emocioná-lo, fazê-lo pensar, enfim, desestabilizá-lo. A literatura versa sobre o espaço, paisagens e lugares, com a fluidez de quem está a produzir conhecimento junto com a vida e não de forma distante. Nesse sentido, promove um encontro entre diversos saberes e supera o isolamento das disciplinas científicas, lançando um olhar atento acerca das dinâmicas do território e sobre as transformações das sociedades e dos lugares.

\footnotetext{
${ }^{6}$ Para Michel Foucault (2009), a vontade de verdade caracteriza o discurso de busca do saber, ou seja, o discurso científico (moderno). O discurso científico é baseado na separação entre sujeito e objeto, na construção de um só método qualificado como científico, no uso da razão e na desqualificação da emoção, da imaginação e do sonho, além da separação entre o conhecimento classificado como científico e o senso comum, o pensamento religioso e o mítico. É um discurso que ao pretender uma linguagem estritamente objetiva, resulta em um texto hermético, fechado - como reflete Cássio Hissa (2006). Já no discurso literário, observa-se a recusa à obtenção da verdade. A representação literária remete ao mundo, expondo-o, mostrando-o, fingindo o mundo, duplicando-o (sem que duplicação signifique cópia).
} 
Dessa maneira, parte-se do pressuposto de que a obra literária e o texto compreendido como estritamente ficcional devem ser interpretados a partir de diálogos travados com outros autores e textos, inclusive com textos teóricos e científicos sem que se estipule algum tipo de hierarquia entre tais textos. Assim, a análise das novelas de Corpo de Baile proposta efetua um deslocamento de tais textos para um mesmo nível que permita o diálogo e a complementação entre os discursos científico e literário. Parte-se do texto, pensando-o como objeto dotado de significação e, simultaneamente, produto de criação ideológica, ou seja, resultante de contextos históricos, sociais e culturais. O interior do texto é dialógico, pois configura-se como espaço de diálogo entre os interlocutores e entre outros textos (BRAIT, 1997).

As produções literárias, de caráter mais ou menos ficcional, são, tal como as obras e livros de teor científico, representações sobre o espaço e sobre os lugares: são interpretações. Enquanto o paradigma da ciência moderna elege a ciência como interpretação mais verdadeira (e, portanto, mais importante), a literatura produz leituras menos pretensiosas e que podem convergir aos caminhos percorridos pela ciência geográfica na direção da construção de perspectivas amplas, integradas e multifacetadas da sociedade e da natureza. Tanto leituras de cunho artístico quanto de caráter científico podem contribuir para a percepção das dinâmicas territoriais, das nuances da paisagem e da força dos lugares, para ver aquilo que escapa do inconsciente e do automatismo do cotidiano. São leituras, portanto, críticas e que, justamente pelo teor crítico, podem contribuir com novos entendimentos que não estão postos pelo senso comum.

Milton Santos já indicava que o "maior erro que a geografia cometeu foi o de querer ser ciência, em vez de ciência e arte" (SANTOS; HARAZIM, 2011, p. 169). A aproximação da geografia com o método de pensamento estritamente científico desconsiderou algumas importantes contribuições, devido ao simultâneo distanciamento da disciplina em relação à literatura, à poesia e à filosofia - campos do conhecimento interdependentes e ricos para a reflexão geográfica. Tal distanciamento vem sendo, a partir de diversos movimentos teóricos e novas posturas intelectuais, questionado e um dos 
resultados de novos arranjos teóricos e metodológicos é a área de estudos localizada entre geografia e literatura. Ainda que as considerações teóricas sobre as possibilidades de diálogo entre as duas áreas estejam em franca construção e debate, cabe pontuar algumas questões fundamentais.

O interesse pelos textos literários remete à geografia regional francesa. A partir da década de 1970, com a emergência da geografia humanista e da geografia crítica, a literatura começou a ser utilizada com mais frequência e, portanto, tratada com mais rigor (BROSSEAU, 2007). As abordagens da literatura estariam presentes em duas correntes do pensamento geográfico. A geografia humanista, interessada na transcrição da experiência dos lugares, e a geografia crítica, focada na literatura realista e na sua crítica à realidade e à ideologia dominante. Ambas as perspectivas são marcadas pela tendência de discussão conceitual amplamente realizada na área dos estudos literários e, em alguma medida, já ultrapassada.

No que diz respeito à abordagem da geografia humanista, é possível observar uma preocupação recorrente em tratar as obras literárias como fonte documental ou em incorporar as obras pelo caráter estético sem o tratamento conceitual adequado no que diz respeito à produção, recepção e percepção crítica sobre ideologias pertinentes ao contexto histórico e geográfico das obras. Com relação à abordagem da geografia crítica, a ênfase excessiva no suposto caráter ideológico da obra acaba por simplificar mecanismos de criação estética e culturais que se baseiam na idéia de que a literatura é um produto da ideologia dominante. É de se perguntar se as abordagens da geografia com relação à literatura concebem as obras apenas como objeto de estudo ou se dialogam também com o arsenal crítico dos estudos literários. Observa-se que grande parte dos trabalhos limita-se a analisar as obras articulando-as às categorias lugar, paisagem e, também, espaço ${ }^{7}$.

Nesse sentido, seria fértil para o pensamento geográfico a abertura de um convívio mais aprofundado com a literatura (obras e estudos), na qual se

\footnotetext{
${ }^{7}$ Alguns trabalhos devem ser citados como exemplos de abordagens precursoras que levaram em consideração as interpenetrações entre geografia e literatura. Além de Carlos Augusto Monteiro (2002), fazemos menção a autores como Fernando Segismundo (1949), Lívia de Oliveira (2002), Eduardo Marandola Jr. (2005), Maria Amélia Vilanova Neta (2005), Lúcia Helena Gratão (2006), Carlos Fuentes (2007) e Oswaldo Bueno de Amorim (2008).
} 
ultrapassasse a concepção da utilização superficial das obras para uma suposta análise espacial. Seria necessário, inclusive, que houvesse mais movimentação de conceitos e categorias não só da geografia ou dos estudos literários, mas de outras áreas pertinentes. $O$ desafio para a produção gerada com as geografias literárias seria a recusa da palavra hegemônica que busca legitimar o paradigma disciplinar. Os investimentos mais profícuos para a geografia literária ou literatura geográfica poderiam ser resultantes da incorporação mútua de conceitos trabalhados entre as duas áreas com a finalidade de que tais trabalhos possam, realmente, criar reflexões críticas importantes no sentido de compreensão do contexto socioespacial e cultural.

Postas as premissas metodológicas norteadoras do presente artigo, propõe-se o tratamento do tema da viagem e do deslocamento em Corpo de Baile, a partir de três eixos de interpretação em que a noção de errância, travessia, viagem e peregrinatio são articuladas às indagações sobre a produção de sentido para o deslocamento espacial. São eles: 1- O sistema de mobilidades representado na novela "Dão-Lalalão (O Devente)"; 2- A inversão da figuração convencional do viajante em "Recado do Morro"; 3- A perspectiva dos deslocamentos como travessias individuais em "Estória de Lélio e Lina".

\subsection{O sistema de mobilidades em Dão-Lalalão (O Devente): entre errâncias e travessias}

As imagens do sertão criadas por Guimarães Rosa permitem a visualização dos deslocamentos por entre as bordas das propriedades privadas de grandes extensões, o trânsito de pessoas que animam tais territórios, tornando-os produtivos, interligando-os; pessoas que vagam à margem dos limites dos latifúndios ocupando os rincões menos valorizados ou vivendo "de favor" em terra alheia, como vaqueiros, agregados, meeiros, quase sempre dependentes dos grandes proprietários patriarcais. O contexto socioespacial do sertão rosiano apresenta, portanto, duas facetas: por um lado há a perpetuação das condições daqueles que desfrutam da estabilidade da fixação à terra e, por outro lado, persiste a constante instabilidade vivida por aqueles que, sem a posse de terra, movimentam-se para atender demandas de trabalho ou para fugir da precária condição do homem do campo, em contínua adaptação ao 
sistema econômico, onde o Estado e outras instituições estão praticamente ausentes.

Em geral, as narrativas rosianas ressaltam a característica errante do homem sertanejo em deslocamento por diferentes espaços do meio rural incorporada por personagens estigmatizados ou marginalizados como os ciganos, os loucos, os fora-da-lei, os andarilhos, os eremitas - esses personagens subversivos que recusam e questionam o conjunto de valores, normas e instituições do "centro". Em Grande Sertão: veredas, destaca-se a figura do jagunço - envolta por feitos notáveis e heroísmos. Já em Corpo de Baile, sobressai a presença do trabalhador anônimo, sendo que tanto 0 "jagunço guerreiro" da primeira obra, quanto o "enxadeiro" da segunda, são determinados pela exclusão do sistema econômico dominante. Para refletir sobre a dinâmica de exclusão do sertão, é interessante considerar o par de opostos criado por Guimarães Rosa em uma das passagens de Grande Sertão: veredas, na qual Riobaldo observa a conversa entre o grande fazendeiro Seo Habão e o chefe jagunço Zé Bebelo:

\footnotetext{
Fiquei notando. Em como Zé Bebelo aos poucos mais proseava, com ensejos de ir mostrando a valia declarada que tinha, de jagunço chefe famoso; e daí, sutil, se reconhecia da parte dele um certo desejo de agradar ao outro. Por causa que o outro era diferido, composto em outra séria qualidade de preocupações. E seô Habão, que escutava com respeito, devagarzinho pegava a fazer perguntas, com a idéia na lavoura, nos trabalhos perdidos daquele ano, por desando das chuvas temporãs e do sol grave, e das doenças sucedidas. $O$ que me dava a qual inquietação, que era de ver: conheci que fazendeiro-mor é sujeito da terra definitivo, mas que jagunço não passa de ser homem muito provisório. (Grifos nossos, ROSA, 2001, p. 429).
}

De um lado estaria o ser "movente" — transitório; e de outro, o sujeito fixado - "permanente". O "sujeito de terra definitivo", personificado nos traços do chefe patriarcal, busca manter e impor valores da estabilidade, estimando a estrutura familiar, a propriedade, a produtividade, a herança, a ordem e 0 poder. Já os "homens muito provisórios" - geraizeiros, pequenos produtores, trabalhadores comuns - passam a vislumbrar também a esperança de uma possível mudança de status, por um porvir mais "definitivo", principalmente nos contos de Corpo de Baile. Recusando os valores e modos de vida 
hegemônicos, ou durante suas lutas diárias, certamente o homem-provisório carrega sonhos de uma vida mais digna.

Especialmente em Corpo de Baile, viajar significa, em alguma medida, caminhar por um futuro definitivo. Esse porvir "definitivo" perseguido pelos personagens de Corpo de Baile em quase todos os contos revela o sonho e a ambição de mudança de lugar social. Talvez seja Soropita, personagem principal de Dão-lalalão (O Devente), aquele que mais simbolize a função do deslocamento como busca por mudança de lugar social. Ex-vaqueiro famoso pela valentia, Soropita esconde seu passado de jagunço, do qual o leitor só recebe algumas pistas que sugerem a função de matador de aluguel financiado pelo Estado ${ }^{8}$. Casado com uma ex-prostituta de Montes Claros, ele tenta esconder seu passado de jagunço, assim como a identidade anterior de sua esposa Doralda.

A viagem que o casal realiza para o Ão marca, para Soropita, o abandono da errância como modo de vida para significar uma travessia que permite a transformação de sua própria identidade. Da errância à travessia, Soropita conquista o sonho da estabilidade e da "fixação", o que representa, certamente, o amadurecimento do ex-jagunço e a conquista de um status social respeitável. A estabilidade é conquistada na medida em que Soropita é inserido socialmente no lugarejo, atuando também como comerciante. Mais fixo do que antes, mas ainda "móvel", o ex-jagunço mantém uma vida em trânsito constante entre o lugarejo e Andrequicé, um percurso rotineiro cujo objetivo é repassar oralmente a novela ouvida no rádio à comunidade do Ão.

\footnotetext{
Nessas direções cruzava, habitual: muita semana, vinha e ia até duas vezes. Durante a mocidade afeito a estar sempre viajando distâncias, com boiadas e tropas, agora que se fixara ali nos Gerais o espírito e o corpo agradeciam o bem daquelas pequenas chegadas a Andrequicé, para comprar, conversar e saber. Do povoado do Ão, ou dos sítios perto, alguém precisava urgente de querer vir- segunda, quarta e sexta por escutar a novela do rádio. (ROSA, 2006, p. 471).
}

\footnotetext{
${ }^{8}$ A narrativa não deixa claro ao leitor se Soropita era ou não assassino de aluguel contratado pelo Estado, mas sugere tais suspeitas em função do fato de o personagem ser absolvido judicialmente pelo assassinato de figuras procuradas pelo governo.
} 
A fixação de Soropita, contudo, revela-se mais provisória do que imaginada a princípio. $\mathrm{O}$ apaziguamento das seguras e rotineiras idas à Andréquicé é colocado em risco durante um desses deslocamentos, quando seu caminho é cruzado por o de um amigo antigo, Dalberto. A presença do amigo do passado, acompanhado por uma tropa de vaqueiros, acaba por significar uma insurgência da identidade jagunça já abandonada por Soropita. Mesmo estabelecido em Ão, o personagem se sente ameaçado pela aproximação daqueles que representavam seu próprio passado e, por isso, poderiam revelar ao povo do Ão não apenas seu histórico violento, mas ainda a identidade encoberta de sua esposa.

Soropita, dominado pela tensão e medo de seu passado ser revelado, encontra uma solução na possibilidade de errar para outro rumo ao final da estória, comprando uma fazenda no estado de Goiás. Assim, é por meio de uma nova travessia que poderá ser preservada a identidade do casal e a manutenção do estilo de vida "fixado" de ambos'.

Tomado o exemplo de Soropita e Doralda em Dão-Lalalão, surge novamente um paralelo entre Corpo de Baile e Grande Sertão: veredas no que diz respeito ao tema do deslocamento em cada uma das obras. Em Grande Sertão: veredas, o caráter da errância adquire o tom pejorativo da interpretação cristã-ocidental para o "vagar eterno", onde não há referência de lar (ONFRAY, 2009): o sertão é o espaço da vida "provisória", das guerras, um longo labirinto sem pouso, mais próximo do inferno bíblico do que propriamente do "céu". Em Corpo de Baile é possível também encontrar sujeitos que assumem a errância como modo de vida que, por sua vez, é radicalmente oposto ao conjunto de valores e regras do "centro" da sociedade do sertão; sujeitos cujas existências apontam para as incompletudes e exclusão inerentes ao sistema econômicosocial que predomina. Entretanto, na maioria das novelas da obra em análise, como já elucidado anteriormente, o ato de errância busca outro estatuto, ou

\footnotetext{
${ }^{9}$ Interessante notar também que Soropita, ao final, está prestes a agir violentamente, recorrer à violência física e "fazer justiça", bem ao modo do "sistema jagunço", tão comum em Grande Sertão: veredas. Porém, ele se contém, pois tenta se regenerar do seu passado sangrento e se inserir socialmente, como homem casado. Essa é uma das marcas principais que diferenciam Grande Sertao: veredas de Corpo de Baile: enquanto na primeira obra a violência impera, e lei jagunça exerce poder paralelo ao Estado, em Corpo de Baile, o sertão está em transformação, se aproximando de uma ordem institucionalizada.
} 
seja, a travessia que busca o recomeço, a procura pela referência familiar, pelo "lar": uma trilha direcionada à mudança do "ser errante" para um sujeito mais "definitivo". O caminho de Soropita para as longínquas terras de Goiás ou mesmo sua viagem com Doralda para o Ão remetem a travessias que sugerem o abandono do "vagar sem abrigo" em direção a afirmação de novas identidades.

Se em Dão-Lalalão, as travessias de Soropita e Doralda permitem-Ihes construir novas identidades, em Recado do Morro, a viagem e o deslocamento propiciam a Pedro Orósio reafirmar sua própria identidade.

\subsection{O olhar invertido do viajante dos gerais: o homem telúrico}

Na novela "Recado do Morro", a figuração do viajante é construída a partir de uma inversão nos termos convencionais que baseiam o estatuto ou a identidade de viajante. O homem do sertão, com pouco estudo, analfabeto, que muitas vezes circula pelos rincões em busca de um novo meio de vida ou ao sabor das demandas temporárias de trabalho, diverge radicalmente da identidade de viajante mais disseminada: a grosso modo, aquele que rompe a estabilidade da vida cotidiana com fins de conhecimento, descanso, curiosidade. Os personagens de Corpo de Baile podem ser compreendidos como representação de alguns tipos relacionados à mobilidade espacial, como o nômade e o errante, mas também são relacionados à figura do viajante.

Recado do Morro trata propriamente de uma viagem do tipo expedição científica realizada em comitiva composta por Seo Alquiste, pesquisador ou cientista, Frei Sifrão e Sr. Jujuca, respectivamente um religioso e um estudado filho de fazendeiro (que desempenha o papel de um tipo de cicerone), e dois sertanejos que atuam como guias: Ivo Crônico e Pedro Orósio. O foco narrativo recai sobre os dois últimos, cujos pensamentos e percepções são de domínio do narrador, que narra também o deslocamento da comitiva em desbravamento pelo sertão central de Minas.

$\mathrm{Na}$ expedição, todos, de alguma maneira, viajam. Não somente o cientista estrangeiro, mas, também, os outros personagens, inclusive os "locais", assim chamados por serem nascidos nos Gerais, ainda que não 
residam mais por aquelas terras. Seo Alquiste ou Seo Olquiste é o estrangeiro que viaja para tudo conhecer, tudo ver, tudo anotar, admirado com o novo e com os detalhes múltiplos que compõem a paisagem. Está "(...) em festa de entusiasmo por tudo, que nem uma criança no brincar." (ROSA, 2006, p. 396). Um viajante com lentes de cientista que toma nota de tudo o que vê; figura importante, doutor: "E doutor dos bons, de mão cheia. Homem importantíssimo." (ROSA, 2006, p. 453).

Seo Alquiste é o típico viajante pesquisador, naturalista, interessado em coletar dados geográficos, geológicos e bióticos da região. Em Recado do Morro, contudo, não é o viajante estrangeiro, representado por Seo Alquiste, a referência principal da narrativa. A narrativa inverte o foco tradicional dos relatos e narrativas cujo enunciador é o sujeito com status de viajante, para trazer a perspectiva dos homens-comuns, homens locais que acompanham a comitiva, transformando-os também em viajantes cujas percepções são as mais importantes da narração. Não é seo Alquiste o personagem cujas percepções ganham importância na história, mas as de Pedro Orósio, o guia sertanejo.

Ao realizar referência direta às expedições científicas do século XIX e séculos anteriores pelo interior brasileiro, Recado do Morro também retoma a dimensão das viagens dos colonizadores, nas quais os exploradores europeus eram sempre acompanhados por "locais": negros escravos, índios amansados, serviçais que não possuíam espaço de representação e lugar no discurso de viagem, como reflete James Clifford (2000, p. 65). Nesse sentido, é interessante perceber que Guimarães Rosa nesta novela, bem como em toda sua obra, dá voz e visibilidade aos silenciados e marginalizados.

Uma das grandes inovações do autor, do ponto de vista estético, está na capacidade de introduzir um posicionamento muito próximo entre o narrador e seus personagens, o que evidencia a grande identificação do autor com a matéria popular. ${ }^{10}$ Durante o percurso da estória em Recado do Morro, é

\footnotetext{
${ }^{10} \mathrm{Em}$ Grande Sertão: veredas, por exemplo, quem conta a estória, aquele que realmente possui algo importante a ser dito, é o jagunço iletrado, "contador de caso", e quem escuta, com "fineza de atenção", é o "doutor" da cidade. O mesmo panorama persiste em Corpo de Baile: as estórias ganham versões ora pela perspectiva do menino de família pobre, Miguilim (Campo Geral), ora pelo ponto de vista de vaqueiros, como Grivo (Cara-de-Bronze), Lélio (Estória de Lélio e Lina) e Soropita (Dão-Lalalão), pelo
} 
possível identificar uma subversão do estatuto de viajante padrão, que é estendido também ao homem-comum representado por Pedro Orósio. Diferentemente do olhar estrangeiro direcionado ao exótico ou pela perspectiva científica, o conto enfatiza o prisma afetivo e telúrico do protagonista, que o aproxima das belezas, riquezas e singularidades do sertão:

\begin{abstract}
Pedro Orósio achava do mesmo modo lindeza comum nos seus campos-gerais, por saudade de lá, onde tinha nascido e sido criado. Mas, outras coisas, que seo Alqueiste e o frade, e o seu Jujuca do Açude se referiam, isso ficava por ele desentendido, fechado sem explicação nenhuma; assim, que tudo ali era uma Lundiana ou Lundlândia, desses nomes. De certo, segredos ganhavam, as pessoas estudadas; não eram para o uso de um lavrador como ele, só com sua saúde para trabalhar e suar, e a proteção de Deus em tudo. Um enxadeiro, sol a sol debruçado para a terra do chão, de orvalho a sereno, e puxando toda força de seu corpo, como é que há de saber pensar continuado? E, mesmo para entender ao vivo as coisas de perto, ele só tinha poder quando na mão da precisão, ou esquentado por ódio ou por amor. Mais, não conseguia (ROSA, 2006, p. 397).
\end{abstract}

A passagem acima coloca em pauta o contraste de sentido relacionado ao deslocamento/à viagem para o viajante naturalista europeu e para o viajante dos gerais representado por Pedro Orósio. Enquanto o primeiro observa com estranhamento a paisagem, sendo necessário racionalizá-la a partir de métodos específicos, inventários, notas de campo, croquis e fotografias, o segundo está completamente incorporado aos seus campos-gerais, "debruçado para a terra do chão". Se o espaço é compreendido como objeto frio de análise por Seo Olquiste, em contrapartida ele é "vivido" como sujeito co-existente no território do sertão para Pedro Orósio. Tanto que o recado transmitido ao longo do percurso para o protagonista é emitido por um morro, marco paisagístico e ponto de referência aos viajantes do sertão, vaqueiros e boiadeiros: o Morro da Garça.

A exposição dos limites do personagem em relação à capacidade de estabelecer relações complexas entre o visto e o percebido e articulá-las em linguagem oral, em discurso, evidencia que Orósio é excluído dos diálogos

enxadeiro Pedro Orósio (Recado do Morro), e também por idosos, como a feiticeira Dõ-nhã (Buriti) ou o velho Camilo (Uma estória de amor). 
entre a parte "importante" da comitiva. Sem se pautar por uma lógica racional ou científica, tal como a dos letrados da comitiva, a produção de sentidos para suas experiências é atravessada pelos sentimentos - ódio ou amor, pelo sentimento de pertencimento à região ou à cultura local, ou mesmo de rejeição.

Mais do que um guia cuja importância se limita a fornecer informações aos letrados e estudiosos, Pedro Orósio toma o lugar de enunciador da viagem sendo a grande referência da novela e o principal envolvido no recado repassado e transmutado por vários personagens ao longo do caminho. Assume em "Recado do Morro", a figuração do viajante telúrico dos gerais, invertendo o perfil do viajante tradicional para o estatuto do "viajor", do "viageiro" 11 .

O sentido que a viagem assume para o personagem Pedro Orósio é o de regresso ao lar, viagem por sua terra natal, os gerais, de retorno às raízes. Ao perder interesse pela figura do viajante estrangeiro Seo Alquiste - "Mas achava mais graça nenhuma, no Seo Olquiste, sempre nas manias de remexer e ver, e perguntar, e tomar o mundo por desenho e escrito." (ROSA, 2006, p. 437) - Pedro Orósio envolve-se na verdadeira viagem que passa a ser importante na obra: o seu retorno ao gerais. Percorrer a região na qual nasceu e foi criado, desperta sentimentos ambíguos: suas impressões variam entre orgulho de sua terra, "Medido, Pedro Orósio, guardara razão de orgulho, de ver o alto valor com que seo Alquiste contemplara o seu país natalício(...)" (ROSA, 2006, p. 415), mas também por um desejo de voltar, sempre titubeante:

\begin{abstract}
Ah, quem-sabe, trovejasse, se chovesse, como lembrando longes tempos Pê-Boi talvez tivesse repensado mesmo sua ideia de parar para sempre por lá, e ficava. Mas, ele assim, a saudade não tinha pressa, que ela é outro nome da água da distância - se voava embora que nem pássaro alvo acenando asas por cima de uma lagoa secável. E o que ele mais via era a pobreza de muitos, tanta míngua, tantos trabalhos e dificuldades. Até lhe deu certa vontade de não ver, de sair dali sem tardança. (ROSA, 2006, p. 416)
\end{abstract}

\footnotetext{
11 O trabalho de Ana Maria Machado (2003) reforça tal argumento ao revelar o significado do nome do protagonista: Pedro como pedra, Orósio como soma de oros ("montanha") e ósio ("escolhido"). Seu homólogo corresponde à pedra, montanha, terra, ou seja, elementos que o associam ao "lugar-sertão". Além disso, seus apelidos remetem a outro tema que o acompanha, o boi, animal ligado à sua lida como vaqueiro (Pê-boi, Pêboizão) e também ao chão (Chãbergo), planície, simplicidade, que o liga novamente ao chão, ao solo, à terra.
} 
De alguma maneira, Pedro Orósio parece amadurecer durante a viagem, volta e meia pensando em parar, estabilizar, talvez voltar para os gerais e definir compromisso amoroso, apesar de ser mulherengo. A viagem o faz refletir sobre si próprio, ajuda a definir melhor sua própria identidade, a de rei dos gerais, como no desencadeamento final da narrativa: "Ao sim, tinha viajado, tinha ido até princípio de sua terra natural, ele Pedro Orósio, catrumano dos Gerais. Agora, vez, era que podia ter saudade de lá, saudade firme." (ROSA, 2006, p. 463). Há, portanto, o sentido de reencontro com as raízes e sua identidade, inclusive ao compreender que o recado enviado pelo morro havia afinal salvado sua própria vida, adiantando-lhe a emboscada preparada para ele.

\subsection{Deslocamento como peregrinatio: Estória de Lélio e Lina}

As concepções elaboradas por Benedito Nunes (1969) colocam-se também como uma importante perspectiva para refletir sobre os sentidos do deslocamento em "A Estória de Lélio e Lina", outra narrativa de Corpo de Baile. Experiência do ser humano que se lança ao sertão para transformar e ser transformado, a viagem é vislumbrada não apenas pelo deslocamento espacial, mas, sobretudo, pelo desvio metafísico, que abre novos horizontes aos sujeitos moventes, como oportunidade para o olhar interior. No caso da obra de Guimarães Rosa, se o sertão transcende seu destino de moldura narrativa, para se conformar em personagem co-protagonistas da narração, a viagem também irá configurar-se a partir do prisma da transcendência.

Nunes (1969) observa que a espacialidade do sertão em Guimarães Rosa se confunde com a própria existência dos personagens. A fusão entre sertão e existência se dá pela expressão de uma visão da vida humana enquanto peregrinatio, viagem sempre recomeçada. Os homens e mulheres da obra rosiana, além de viajantes, são a própria viagem - objetos e sujeitos da travessia, em cujo processo o mundo se faz.

No caso da narrativa de "A Estória de Lélio e Lina", a noção do movimento despretensioso de Lélio aparece evidente já no início do conto, 
quando o protagonista chega à fazenda do Pinhém, propriedade do patriarca Seo Senclér, após viver desilusões amorosas em outros "fins de rumo" do sertão. "Estava de alma esvaziada, forro de sombra toda atrás, nenhum peso de pena, nem preocupo, nem legítima saudade" (ROSA, 2006, p. 252); chegara sem estar preso a nada, nem a ninguém: "estou alheio", dizia, "solto, solto". É importante notar que por estar "solto", Lélio tem liberdade suficiente para colocar-se diante do imprevisível. Por meio da mobilidade, o lugar cotidiano, espaço vivido anteriormente, onde "tudo acontecia já emendado e envelhecido", abre-se como possibilidade de fluxos por lugares extrovertidos:

\begin{abstract}
Lélio se estendeu, feliz de seu bom descanso. Já se abençoava de ter vindo para o Pinhém; principalmente, se conseguia solto, dono de si e sem estorvo. Era um novo estirão de sua vida, que principiava. Antes, nos outros lugares onde morara, tudo acontecia já emendado e envelhecido, igual se as coisas saíssem umas das outras por obrigação sorrateira - os parentes, os conhecidos, até os namoros, os divertimentos, as amizades, como se o atual nunca pudesse ter uma separação certa do já passado; e agora ele via que era dessa quebra que a gente precisava às vezes, feito um riachinho num ribeirão ou rio precisa de fazer barra. (ROSA, 2006, p. 254)
\end{abstract}

A interrupção da fluidez de seu caminho ${ }^{12}$ permitiria a experimentação de um "outro mundo" essencialmente pela perspectiva da busca amorosa. $\mathrm{O}$ movimento interno da novela inicia e termina com uma viagem: Lélio abre o ciclo com sua chegada à fazenda após decepções amorosas e encerra quando "dispersa" sem rumo junto à Dona Rosalina, uma velhinha "diversa de todas as outras pessoas" (ROSA, 2006, p. 305), estabelecendo uma relação muito íntima desde o primeiro encontro, o que desencadeia uma atração afetiva e espiritual recíproca.

Após completar um ano vivenciado na fazenda do Pinhém e ainda antes da decisão de partir com Lina, o protagonista demonstra uma aparente falta de critério para a escolha de sua pretendente ao longo da estória, ao confundir com frequência o falso amor e o verdadeiro amor. Seja pela idealização e

\footnotetext{
${ }^{12}$ A "quebra" a que Lélio se refere remete justamente ao afluente de águas monótonas que flui para o rio principal, imponente, fluidez intensa que não tem o controle do destino Neste sentido, a personalidade fluida de Lélio pode ser comparada à travessia de Riobaldo em Grande Sertão: veredas. Ana Maria Machado atém-se ao nome do protagonista Rio baldo para sugerir uma interpretação "fluvial" sobre o personagem: "marcando as tantas mudanças de curso de um personagem que não se fixa num só caminho e que, em seu permanente fluir, toma o rio como modelo" (Machado, 2003, pg. 62-63).
} 
encantamento superficial pela moça da cidade (Sinhá), seja pela força sensual de Jiní, ou do amor enganoso por Manuela e Mariinha, em todas as situações a ingenuidade de Lélio vem à tona. Apenas com o transcorrer do tempo na fazenda, das diversas experiências e com o contato com Dona Rosalina, ele é capaz de amadurecer e, enfim, empreender uma nova condição de deriva. Os dois partem ao final da estória em nova "travessia".

Assim, a errância reinicia seu ciclo e a mirada é ampliada para além dos chapadões: “'... Chapada e chapada, depois você ganha o chapadão, e vê largo...' Lélio governava os horizontes" (ROSA, 2006, p. 383). Com o ciclo se fechando na fazenda do Pinhém, ele percebe que as experiências de amor que vivera até ali ora eram ilusórias, ora apenas carnais, ou então incompletas e consegue compreender tudo o que passa ao seu redor apenas pela cumplicidade, afeto, sinceridade e amor em Lina, contrariando as expectativas do leitor, do próprio protagonista e do crivo moral dos moradores da região.

A essência da viagem de Lélio remete a ideia de acaso, deriva e errância. Se no início da novela ele imagina as terras do Pinhém como possível morada definitiva (inclusive marcando em uma árvore aonde seria o local ideal para construir sua casa), e projeta o casamento com Manuela ou Mariinha, as moças solteiras da região, seu caminho é desobstruído pelo imprevisto, ou seja, pela atração afetiva pela sábia Lina - sua conselheira espiritual. Tudo isso deixa transparecer uma perspectiva da viagem enquanto possibilidade também de aprendizado, como uma viagem iniciática ou de iniciação. Se no caso da novela em questão o plano amoroso é o ponto central da narrativa, a transformação se dá principalmente em torno da experiência interna e externa de Lélio, ambas caracterizadas pela desterritorialização, relocalização e deriva, viagem "de fora" e "de dentro" do sujeito à procura de novos horizontes, recorrente também nas travessias de Grande Sertão: veredas, as quais as noções de dispersão, recomeço e esperança são fundamentais.

\section{RESULtAdOS E DISCUSSÃo}

A experiência do deslocamento exposta neste artigo por meio dos fluxos espaciais retratados em Corpo de Baile retoma uma discussão primordial das 
questões espaciais ${ }^{13}$. Ir e vir são movimentos primários da construção identitária do ser humano, tal como observam Mircea Eliade (1993) e Paul Ricouer (1994) ao refletirem sobre os aspectos lineares e circulares do tempo em diversas práticas, sejam religiosas ou culturais. Encaminhando tal conceituação para o contexto do sertão rosiano, evidenciam-se os dilemas e os anseios dos personagens que transcendem o texto literário para conduzir a uma interpretação multifacetada e estimulante sobre as mobilidades humanas.

Os resultados da discussão proposta - uma reflexão conceitual sobre a subjetividade e os aspectos histórico-culturais presentes em Corpo de Baile se relacionam aos desdobramentos conceituais ligados à ideia de errância, travessia e peregrinatio. Tais termos representam sentidos diversos dados ao conceito mais geral de deslocamento. É possível compreender, também, que os termos errância, travessia e peregrinattio possuem significado próximo e relacional, de modo que busca-se apresentar, a seguir, os atravessamentos entre tais noções analisando as novelas de Corpo de Baile tratadas neste artigo.

Em primeiro lugar, no que se refere à noção de travessia, é importante considerar as inúmeras facetas do deslocamento apresentadas: movimento cotidiano do vaqueiro ou trabalhador assalariado em trânsito coletivo ou individual; parte da vida de sujeitos marginalizados que vagueiam como nômades perseguindo imagens ou lidando com a vida de um modo mais visceral e menos ditado por convenções sociais; ex-jagunços e ex-bandidos que, como observado no caso de Soropita, buscam reconstruir sua identidade sob referências socialmente aceitas; jovens, como Lélio e Pedro Orósio, para os quais a viagem representa um tipo de iniciação: oportunidade de aprendizagem e amadurecimento.

A mobilidade em Corpo de Baile pode ser compreendida a partir da noção de fixação e estabilidade. Assim, para Pedro Orósio - viajante telúrico,

\footnotetext{
${ }^{13}$ Cabe ressaltar a obra de Milton Santos (1996) e o esforço de construção de uma ontologia do espaço em que encontram-se indissociáveis as categorias espaço e tempo, de modo que o autor conceitua o espaço geográfico como um híbrido entre o sistema de objetos e o de ações. Dessa maneira, a discussão abordada tangencia as discussões espaciais, na medida em que entende-se o deslocamento, a mobilidade e o fluxo como componentes das dinâmicas cuja compreensão é imprescindível para a compreensão sobre o próprio espaço geográfico.
} 
viajante "local", o sentido de seu próprio deslocamento remete a um suposto regresso ao lar, ao "lugar de origem", berço da existência- lugar fixo (origem). Para Soropita e Doralda, nas entrelinhas de Dão-Lalalão, o esforço do deslocamento é de abandono da errância em função do sonho por um locus definitivo. Assim, a busca por permanência e estabilidade estimula a reflexão sobre a construção de uma imagem negativa associada à errância.

Em segundo lugar, para refletir sobre o conceito de travessia, é indispensável discutir o caráter depreciativo ligado à ideia de errância. A errância, ou seja, O vagar sem fim e sem norte, faz parte de um discurso que tem o propósito de construir uma caricatura negativa e pejorativa do deixar-se afetar pelo mundo, da experimentação originária do vagar que, afinal, contrapõe-se ao modo de vida produtivo baseado nos ritmos do trabalho assalariado. O significado de errância em Corpo de Baile, contudo, não é permanente: o errante não seria um tipo de sujeito condenado como assimilado pela tradição bíblica. Embora o termo evoque trauma e separação, presentes em qualquer migração, a noção de errância repercute na obra como uma ideia da esperança, de mudança e de recomeço, como visto nos casos de Soropita e Lélio.

Se o sonho por estabilidade e fixação revela-se impossível em DãoLalalão e foge ao desejo de Pedro Orósio em sua viagem, bem como ao desejo de Lélio, é possível encontrar nas novelas a vinculação da viagem à noção de travessia - passagem, mudança. Dessa maneira, retoma-se a reflexão sobre a noção de travessia, que é também encontrada em histórias míticas, como, por exemplo, no episódio do grande dilúvio, comum a várias culturas, cuja versão mais conhecida é o relato de Noé e sua arca, encontrado no Gênesis, o primeiro livro da Bíblia. Na narrativa judaico-cristã, Deus envia um dilúvio para livrar a terra de uma humanidade corrupta, e escolhe Noé, um bom homem, para construir uma arca que abrigasse sua criação durante a inundação. A viagem de Noé, mesmo sem destino certo e orientação, e entregue aos caprichos de (um) Deus que, por fim, estabelece um pacto com a humanidade a favor da vida na terra, simboliza uma transição. A questão mais central nessa narrativa não é o lugar da partida ou da chegada da arca — não se sabe ao 
certo onde Noé desembarca -, mas, principalmente, a travessia. O que aparece como interesse essencial é a reconstrução do lar, somente tornada possível com a realização da travessia que, por sua vez, representa, em termos mais amplos, o recomeço da civilização. A viagem de Pedro Orósio na qual o retorno à sua região natal representa um risco de morte, seja em função da emboscada anunciada pelo recado do morro, seja em função dos efeitos que o contato com sua terra natal (seu passado e origem) provocam na constituição de sua identidade.

Da mesma forma, o conceito de travessia é complementado pela noção de peregrinatio sugerida na leitura da Estória de Lélio e Lina, uma vez que o abandono da errância para a criação de novos movimentos de travessia não pode ser entendido como processo linear, mas cíclico que é impulsionado e desenvolvido também por condições de causalidade e imprevisibilidade que a viagem proporciona.

\section{CONCLUSÕES}

Para responder as questões levantadas a respeito das identidades dos viajantes ficcionais em análise, diversas imagens a respeito dos enredos das novelas foram colocadas em evidência. Em alguma medida, a representação do mundo por intermédio da literatura impulsionou um novo olhar para discutir a viagem enquanto superação do próprio ser em contato com realidades ainda inexploradas. Ora pelo do ponto de vista do contexto histórico-social, ora pelo viés simbólico/metafísico, os rumos individuais dos personagens pressupõem que os motivos das ações são elencados de forma distinta para dar vazão aos seus grandes dilemas. Apesar de cada um deles ter sua especificidade ligada à história de vida e suas internalidades, a ação se constrói pela constelação de sentidos que a viagem abre na travessia desses seres moventes.

Conclui-se que para os personagens de Corpo de Baile a viagem ou o deslocamento não representam um tipo de método ou prática cultural que poderia ser taxada como prática de lazer, mas como a própria ideia de experiência, vida e morte: amadurecimento e aprendizagem, busca por melhores condições de vida, ascensão social, fortalecimento dos vínculos 
identitários. O potencial do deslocamento em Corpo de Baile, portanto, traduzse com a construção de caminhos orientados por ciclos que conectam partida e retorno, mas que não fornecem a imagem de exercício finalizado, emoldurado, com bordas bem definidas: imagem simplificadora da ideia de viagem e a própria ideia de vida. Afinal, desde a partida - e antes mesmo dela - já se está viajando. Após o retorno, também, já se viaja. Há deslocamentos nos interiores da viagem. A ideia de viagem em Corpo de Baile se vincula às noções de ciclos que se sucedem no movimento da vida e da experiência.

\section{REFERÊNCIAS BIBLIOGRÁFICAS}

AMORIM FILHO, Oswaldo Bueno. Literatura de explorações e aventuras: as "viagens extraordinárias" de Júlio Verne. In:Sociedade \& Natureza, Uberlândia, 20(2): 107-119, 2008.

BRAIT, Beth. Bakhtin, dialogismo e construção do sentido. Campinas, SP: Ed. da UNICAMP, 1997.

BROUSSEAU, Marc. Geografia e Literatura. In: CORRÊA, Roberto L.; ROSENDAHL, Zeny. (Orgs.). Literatura, Música e Espaço. Rio de Janeiro: Eduerj, p. 17-78. 2007.

CLIFFORD, James. Culturas viajantes. In: ARANTES, Antonio Augusto (Org.).

O espaço da diferença. São Paulo: Papirus. 2000. Capítulo 3. p. 50-79.

ELIADE, Mircea. O mito do eterno retorno: arquétipos e repetição. Lisboa; Rio de Janeiro: Ed. 70, 1993.

FOUCAULT, Michel. A ordem do discurso: aula inaugural no Collège de France, pronunciada em 2 de dezembro de 1970. 18 ed. São Paulo: Loyola, 2009. 
FUENTES, Carlos. Geografia do romance. (trad. Carlos Nougué) Rio de Janeiro: Recco, 2007.

GRATÃO, Lúcia Helena B. Da projeção onírica bachalerdiana, os vislumbres da geopoética. In: OLIVEIRA, Lívia etal. (org.). Geografia, percepção e cognição do meio ambiente. Londrina: Edições Humanidades, P.165-189, 2006.

HISSA, Cássio E. Viana. A mobilidade das fronteiras: inserções da geografia na crise da modernidade. Belo Horizonte: Editora UFMG, 2006.

MACHADO, Ana Maria. Recado do nome: leitura de Guimarães Rosa à luz do nome de seus personagens. Rio de Janeiro: Nova Fronteira, 2003.

MARANDOLA JR., Eduardo. Humanismo e a abordagem cultural em geografia, In: Geografia, Rio Claro, AGETEO, v. 30, n. 3, p. 393-420, set./dez. 2005.

MARTINS, Nilce Sant'Anna. O léxico de Guimarães Rosa. São Paulo: EDUSP, 2008.

MONTEIRO, Carlos Augusto de Figueiredo. O mapa e a trama: ensaios sobre o conteúdo geográfico em criações romanescas. Florianópolis: Editora da UFSC, 2002.

NUNES, Benedito. O dorso do tigre: ensaios. São Paulo: Perspectiva, 1969.

OLIVEIRA, Lívia de. Sertão rosiano: percepção, cognição e afetividade geográfica.In:SCRIPTA, Belo Horizonte, v. 5, n. 10, p. 234-242, 2002.

ONFRAY, Michel. Teoria da viagem: poética da geografia. Porto Alegre: L\&PM, 2009.

RICOEUR, Paul. Tempo e narrativa. Campinas: Papirus, 1994. 
ROSA, João Guimarães. Corpo de baile. Rio de Janeiro: Nova Fronteira. 2006.

ROSA, João Guimarães. Grande sertão: veredas. Rio de Janeiro: Nova Fronteira, 2001.

ROSA, João Guimarães. Primeiras Estórias. Rio de Janeiro: MEDIA fashion, 2008.

ROSA, João Guimarães. Sagarana. Rio de Janeiro, RJ: Nova Fronteira, 1984.

SANTOS, Milton. A natureza do espaço: técnica e tempo, razão e emoção. São Paula: HUCITEC, 1996.

SANTOS, Milton; HARAZIM, Dorrit. O mundo não existe. In: HISSA, Cássio E. Viana (org.). Conversações: de artes e de ciências. Belo Horizonte: Editora UFMG, 2011.

SEGISMUNDO, Fernando. Literatura e Geografia. In: Boletim Geográfico. Rio de Janeiro, n. 76, p. 327-332, jul. 1949.

SOARES, Claudia Campos. Considerações sobre Corpo de baile. In: Itinerarios. Araraquara. v. 25, p. 41-68, 2007.

VILANOVA NETA, Maria Amelia. Geografia e literatura: decifrando as paisagens dos mocambos do Recife. Dissertação (Mestrado) - Universidade Federal do Rio de Janeiro, Programa de Pós-Graduação em Geografia, Rio de Janeiro, 2005. 